\title{
La eficacia cultural en la comunicación de las ONGD:
}

Leyre Navarrete Emmanuel

leyrenavarrete@gmail.com 
I. Resumen

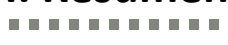

Ante la diversidad y pluralidad de comunicaciones por parte de las ONGD hoy en día, es importante recordar la particularidad del tercer sector y la responsabilidad de estas organizaciones como interlocutores sociales que fomenten la sensibilización de la ciudadanía, su educación, la lucha por la justicia social y contra las relaciones de poder, tanto local como globalmente. Tratándose de actores con responsabilidad social ante la ciudadanía, es necesario que sus discursos estén guiados por dichos valores sin caer en la contradicción de que la necesidad recaudatoria suponga perpetuar estereotipos y situaciones generadoras de desigualdad que ellas mismas luchan por eliminar.

Habiendo encarnado un aparente giro en los discursos tradicionales de las ONGD, la campaña \#CierraUnicef se analiza en este artículo con una mirada constructiva, utilizando como método de análisis el decálogo del Vademécum para una Información Internacional Responsable, del proyecto DEVREPORTER, con el objetivo de localizar posibles elementos generadores de desigualdad en las relaciones de cooperación, así como avances positivos en dicha dirección que faciliten el camino hacia una comunicación desde las ONGD más inclusiva, empoderadora y respetuosa sobre la que seguir construyendo.

Si bien esta comunicación cuenta con ciertas elecciones narrativas que cumplen algunos criterios de ese decálogo, vemos cómo detrás de esa narración se incluyen elementos que perpetúan los marcos tradicionales de la cooperación basados en la desigualdad, en los que el asistencialismo rige las relaciones nortesur y en las que se presenta a las ONGD como salvadoras, portadoras de soluciones inalcanzables por unos protagonistas incapaces $y$ estáticos, que dependen en gran medida de las ONGD para avanzar.

Palabras clave: comunicación, ONGD, tercer sector, eficacia cultural, advocacy, cambio social

\section{Introducción}

Este artículo tiene como objetivo el análisis de la comunicación llevada a cabo desde Unicef en su campaña \#CierraUnicef de 2017 desde una perspectiva de eficacia cultural, que aborde la cooperación y el desarrollo desde discursos libres de estereotipos que respeten la dignidad de sus protagonistas.

La diversidad y pluralidad de ONGD (concepto amplio y genérico pero que en adelante usaré, dado que es el más extendido, al referirme al tercer sector estructurado de cooperación) es una 
realidad muchas veces abrumadora hoy en día. La comunicación de las ONGD forma parte cada vez más de nuestro entorno, en el que los medios de comunicación nos acercan su mensaje y, si bien es cierto que cada una de ellas aborda la cooperación desde un enfoque y estrategias propios, es innegable que en la actualidad existen numerosos casos en los que el afán recaudatorio y estrategias que recuerdan al más puro marketing han desplazado la eficacia cultural de su discurso.

Partiendo de esa realidad plural de ONGD que comentamos, se hace imprescindible abordar las peculiaridades y responsabilidades que diferencian al tercer sector de otros sectores sociales, como las empresas o el Estado. Como Nos Aldás explica, estas organizaciones cuentan con unos objetivos de trabajo colectivo orientados al bien público y unas formas de trabajo cooperativas, por y desde la solidaridad (2007: 210-212). Esas características rigen -o deberían regir - el trabajo y la visión de estas organizaciones, que como actores sociales fundamental para la concienciación de las desigualdades globales, cuentan con responsabilidades comunicativas que parten de responsabilidades educativas y de incidencia política por la justicia social y la erradicación de la pobreza (FCONGD, 1997; CONGDE, 1998).

Así, los propósitos de las ONGD están íntimamente ligados al concepto de advocacy (utilizado en inglés dada su complejidad de traducción al español por falta de un término concreto), que combina una «responsabilidad de sensibilización más una pedagogía política y cultural y una incidencia política, legislativa y cultural hacia procesos de cambio social» (Nos Aldás et al., 2012: 212). En estas organizaciones recae, por lo tanto, una responsabilidad comunicativa muy importante: al carácter específico de sus valores y objetivos se une la gran incidencia que sus comunicaciones tienen en la ciudadanía. Las realidades y las problemáticas que las campañas de las ONGD reflejan a menudo retratan otras totalmente ajenas a las del público al que se dirigen, en cuyo frenético día atisban de pasada lo que puede estar sufriendo alguien al otro lado del mundo a través de la marquesina de la parada de autobús, el anuncio de televisión entre programa y programa, o la foto o vídeo de Facebook que aparece en su muro cuando abre la red social.

Uno de los principales retos de la comunicación de las ONGD y el que se erige como su horizonte es la eficacia cultural, desde la que localizar la violencia cultural existente en los discursos, y ver cómo transformar esa violencia en cultura de paz. Se trata de una comunicación para el cambio social desde el advocacy (Nos Aldás et al., 2012), que sensibilice, forme y eduque, sin caer en los estereotipos tan habituales del discurso hegemónico actual, y promueva una comunicación horizontal. 
Esta eficacia cultural parte de la performatividad del discurso (Austin, 1976) y su acción comunicativa (Habermas, 1987) que puede traducirse en la implicación social a partir de las comunicaciones de las ONGD desde su transversalidad (Nos Aldás et al., 2012: 214). La importancia de la eficacia cultural de la comunicación de las ONGD deriva a su vez de la indiscutible influencia de sus discursos en la construcción de la realidad, en este caso del desarrollo y la cooperación, por parte de los que los reciben. Cada una de las elecciones que se hacen a la hora de comunicar (lenguaje, imágenes, protagonistas, perspectiva de enfoque, etc.) se traduce en «la concepción que el emisor tiene de la realidad de la que habla, su relación con esas realidades y la reacción que busca en los públicos. Cada mensaje no solo realiza una propuesta de solidaridad determinada, sino que refleja la solidaridad del emisor y de su propia comunicación» (Nos Aldás, 2010: 15).

Sin embargo, la realidad es que somos testigos y receptores de comunicaciones de ONGD en las que el enfoque asistencialista presenta a sus protagonistas como víctimas incapaces, inmóviles, sin contexto ni historia, que necesitan de nuestra "caridad" y la de las ONGD para mejorar su vida. A su vez, la implicación de la ciudadanía se hace desde una relación vertical en la que se asume que su único poder es el monetario. El trabajo de Nos, Iranzo y Farné expone esta realidad actual de las ONGD, en la que se plasma esta crisis de valores y tras la que se hace necesario que las ONGD no sigan promoviéndose como "catalizadoras y movilizadoras de recursos [...] para asumir como función principal la de agentes de cambio» (De Souza, 2009: 701; Santolino, 2010). Se hace necesario cambiar esa "solidaridad del mínimo esfuerzo" fomentada por las ONGD (Erro Sala 2000; 2003a; 2003b; 2006, entre otros; Ballesteros 2002; Rizzardini 2002).

$\mathrm{Si}$ pretendemos mejorar la eficacia cultural de esas comunicaciones, los compromisos que la ciudadanía y los poderes públicos adopten, y romper con los estereotipos y las relaciones de poder que justifican a la vez que legitiman la desigualdad, necesariamente debemos cambiar el marco (framing) desde el que se comunica, así como abandonar los marcos que han promovido y mantenido esta situación. George Lakoff en su teoría de los marcos los define de la siguiente manera:

las estructuras mentales que nos permiten a los seres humanos comprender la realidad $y$, en ocasiones, crear lo que nosotros consideramos que es la realidad (...). Estructuran nuestras ideas y nuestros conceptos, conforman nuestra manera de razonar e incluso repercuten en la manera en la que percibimos y actuamos. La mayoría de las veces usamos los marcos de forma inconsciente y 
automática; los usamos sin darnos cuenta. (2006: 61 citado en Darton

y Kirk 2011, y Mesa 2013).

Los marcos son la manera que tenemos de ver, explicar y dar sentido al mundo. Sin embargo, para cambiar esos marcos no basta con ir contra ellos. En su trabajo Visibles y transgresoras, Mesa desarrolla el funcionamiento de esos marcos, partiendo de las aportaciones de Lakoff, y los retos necesarios para su cambio efectivo. Si queremos cambiar los marcos que han recibido los ciudadanos por diversas fuentes, entre ellas las ONGD, y que han contribuido a la construcción de estereotipos y la asignación de roles, no basta con la crítica a esos mismos marcos. Es necesario un cambio de lenguaje y la construcción de marcos alternativos, ya que su denuncia refuerza el marco y la utilización de su mismo lenguaje vuelve a remitirnos a él, haciéndolo más fuerte (Lakoff, 2007; Mesa, 2013). "Cambiar el marco significa promover el cambio social. Cambiar el marco es cambiar el modo que tiene la gente de ver el mundo. Es cambiar lo que se entiende por sentido común». (Lakoff, 2007, citado en Mesa, 2013).

Mesa (2013) promueve la construcción de marcos alternativos, y aunque su trabajo se enfoca a las relaciones de desigualdad entre hombres y mujeres, esos marcos propuestos sin duda nos son útiles para aplicar esos marcos alternativos en el caso específico de las relaciones de desigualdad en el ámbito del desarrollo y la cooperación (desigualdades norte-sur, países desarrollados frente a países subdesarrollados). Los marcos tradicionales de mujer víctima frente a hombre héroe tienen una relación directa indudable en las relaciones de poder de hombre blanco poderoso y salvador, en contraste con persona de color pobre, desvalida e incapaz. A partir de estos marcos alternativos propuestos, defendemos un retrato de las situaciones que no aísle de la realidad, que dé voz a sus protagonistas y que los empodere exponiéndolos en su contexto. Es necesario abandonar los discursos en los que se priva de voz al protagonista representándolo en situaciones que incitan a la evocación de emociones como la pena o la culpa (como, por ejemplo, un niño de África, retratado solo, sin contexto y con el vientre abultado).

Los prejuicios y estereotipos que atribuyen rasgos y roles también se han apoderado de los discursos de cooperación, en los que se discrimina a sus propios protagonistas. Es preciso un cambio en la denuncia, que ponga el foco en las causas y los responsables que propician esa violencia o desigualdad en lugar de en las víctimas, para evitar que esa sobrerrepresentación de diversos colectivos como víctimas fomente una visión estereotipada y dicotómica (Mesa, 2013: 31) que ha construido el enfoque asistencialista imperante. Un marco que, como el propuesto de «mujeres visibles y transgresoras», 
"se sustente en estructuras sociales horizontales, abiertas y democráticas, con relaciones basadas en redes que conectan personas activando valores de equidad, colectividad, dinamismo, creatividad, resiliencia y resistencia. Se trata de deslegitimar la lógica de la violencia que pone en juego la vida de los seres humanos para perseguir intereses materiales, ideológicos, de poder o soberanía». (Mesa 2013: 34, a partir de Magallón, 2012a).

Dada la particularidad del tercer sector, debemos recordar la responsabilidad de las ONGD como interlocutores sociales que fomenten la sensibilización de la ciudadanía, su educación, la lucha por la justicia social y contra las relaciones de poder, tanto local como globalmente. Por ello, así como por la relación y efecto directos que tienen en la ciudadanía incidiendo en la forma en que percibe esas realidades tan a menudo lejanas, es importante que sus discursos estén guiados por dichos valores sociales sin caer en que la necesidad recaudatoria por su supervivencia económica siga perpetuando estereotipos y situaciones generadoras de desigualdad.

A partir de esta problemática, el presente artículo tiene el objetivo de localizar en esta campaña, con una mirada constructiva, los posibles elementos perpetuadores de desigualdad en las relaciones de cooperación a través de su comunicación, así como avances positivos que faciliten el camino hacia una comunicación desde las ONGD más inclusiva, empoderadora y respetuosa sobre la que seguir construyendo, al tiempo que tratamos de contestar a la pregunta de si cumplen las campañas de comunicación de las ONGD los criterios para una información internacional responsable.

\section{Objetivos}

Las ONGD actúan a menudo como ventana de la sociedad a problemas del mundo que nos es difícil conocer de otra manera. Por ello, se debe prestar especial atención a la comunicación de estas organizaciones, dado su papel significativo en la transformación social y en la educación de una ciudadanía global crítica, como defienden Nos, Iranzo y Farné (2012). De esta manera, el análisis de la campaña de \#CierraUnicef se abordará desde una mirada de comunicación para el cambio social y transformadora.

En el reto de la comunicación de las ONGD con el horizonte y guía de la eficacia cultural, se hace imprescindible identificar las violencias existentes en los discursos para poder emprender el camino hacia la cultura de paz mediante el cambio social, localizando los estereotipos perpetuadores de desigualdad.

En suma, el objetivo de este trabajo es el de localizar, a través del análisis de la comunicación de la campaña elegida, elementos generadores de desigualdad en las relaciones de cooperación o que no cumplan con los criterios para una información internacional 
responsable, así como aquellos que sí lo hagan, para poder proponer

alternativas específicas para una comunicación horizontal, responsable y eficaz culturalmente desde las ONGD.

\section{Material y método}

El objeto de estudio de este análisis es la comunicación de la campaña \#CierraUnicef del Comité Español de UNICEF (Fondo de las Naciones Unidas para la Infancia), tomando como objeto específico el vídeo de la campaña incluido en su página web, que se difundió por los medios de comunicación.

La muestra se ha elegido por tratarse de una comunicación por parte de una ONGD con cierto giro en el discurso, sin repetir fórmulas a las que la ciudadanía está acostumbrada, y que merece ser analizada tanto por su novedad como por su ambigüedad.

Como método de análisis cualitativo se utilizará el decálogo del Vademécum para una información internacional responsable del proyecto Devreporter. Se contrastará con la campaña para ver en qué medida cumple con sus principios.

\section{Resultados}

Una vez realizado el análisis cualitativo del vídeo de esta campaña a través del Vademécum del Devreporter para observar si se cumplen estos diez principios, los resultados para cada uno de esos principios son los siguientes:

\begin{tabular}{|c|c|c|}
\hline Principio del Vademécum & Ideas principales & Cumplimiento \\
\hline $\begin{array}{l}\text { 1. Favorecer el } \\
\text { "periodismo } \\
\text { soluciones" }\end{array}$ & $\begin{array}{l}\text { - posibles soluciones de los } \\
\text { diferentes actores } \\
\text { - propuestas sociedad civil } \\
\text { - mirada crítica que contribuya } \\
\text { a la reflexión }\end{array}$ & $\begin{array}{l}- \text { No } \\
- \text { No } \\
\text { - No }\end{array}$ \\
\hline $\begin{array}{l}\text { 2. Tratar todos los países } \\
\text { y comunidades con } \\
\text { dignidad. Evitar el } \\
\text { sensacionalismo y la } \\
\text { victimización }\end{array}$ & $\begin{array}{l}\text { - Importancia de vocabulario, } \\
\text { lenguaje escrito y audiovisual } \\
\text { - Evitar lenguaje estereotipado, } \\
\text { discriminatorio y androcéntrico } \\
\text { - No difundir fotografías que } \\
\text { vulneren la dignidad humana y } \\
\text { de los niños } \\
\text { - Pueblos y comunidades como } \\
\text { luchadoras no solo como } \\
\text { víctimas }\end{array}$ & $\begin{array}{l}\text { - Sí } \\
\text { - No } \\
\text { - Sí } \\
\text { - Sí y no }\end{array}$ \\
\hline $\begin{array}{l}\text { 3. Diferenciar la } \\
\text { información periodística } \\
\text { de la comunicación } \\
\text { institucional de las }\end{array}$ & $\begin{array}{l}\text { - Énfasis en la situación de los } \\
\text { países afectados en vez de } \\
\text { solamente información de la } \\
\text { propia ONG }\end{array}$ & $-\mathrm{No}$ \\
\hline
\end{tabular}




\begin{tabular}{|c|c|c|}
\hline organizaciones & & \\
\hline $\begin{array}{l}\text { 4. Mejorar la visibilidad de } \\
\text { los actores de los países } \\
\text { del sur implicados o no en } \\
\text { las acciones de } \\
\text { cooperación internacional } \\
\text { e incluirlos en la } \\
\text { producción } \\
\text { información }\end{array}$ & $\begin{array}{l}\text { - Consultar diversas fuentes, } \\
\text { también del Sur y dar voz a las } \\
\text { poblaciones } \\
\text { - Alianzas norte-sur para } \\
\text { enriquecer, diversificar y } \\
\text { difundir información } \\
\text { - Personas que cuenten sus } \\
\text { propias historias, incluida la } \\
\text { opinión de los niños en lo que } \\
\text { les afecte }\end{array}$ & $\begin{array}{l}\text { - Sí y No } \\
\text { - No }\end{array}$ \\
\hline $\begin{array}{l}\text { 5. Favorecer miradas } \\
\text { amplias sobre los países } \\
\text { del sur: evitar la } \\
\text { «oenegización» de la } \\
\text { información internacional }\end{array}$ & $\begin{array}{l}\text { - Abordar cooperación desde } \\
\text { vertientes múltiples } \\
\text { (económica, política y cultural) } \\
\text { - Perspectiva de las acciones de } \\
\text { la solidaridad internacional }\end{array}$ & - No \\
\hline $\begin{array}{l}\text { 6. Favorecer la } \\
\text { comprensión de los } \\
\text { hechos y su complejidad, } \\
\text { aportando contexto y } \\
\text { causas }\end{array}$ & $\begin{array}{l}\text { - Aportar contexto de } \\
\text { acontecimiento y lugar de los } \\
\text { proyectos } \\
\text { - Aporte datos disgregados (por } \\
\text { sexo, edad o etnia) }\end{array}$ & $\begin{array}{l}- \text { No } \\
\text { - No }\end{array}$ \\
\hline $\begin{array}{l}\text { 7. Promover que la } \\
\text { realidad internacional se } \\
\text { aborde desde los medios } \\
\text { de comunicación locales } \\
\text { para favorecer el } \\
\text { conocimiento mutuo }\end{array}$ & $\begin{array}{l}\text { - Conocer problemáticas e } \\
\text { intereses locales, de proximidad } \\
\text { - Mostrar prácticas locales que } \\
\text { puedan ser inspiración a nivel } \\
\text { internacional }\end{array}$ & $\begin{array}{l}- \text { No } \\
-\mathrm{No}\end{array}$ \\
\hline $\begin{array}{l}\text { 8. Tomar perspectiva y } \\
\text { cubrir los hechos desde su } \\
\text { dimensión global para } \\
\text { favorecer la comprensión } \\
\text { de las interdependencias } \\
\text { presentes y futuras }\end{array}$ & $\begin{array}{l}\text { - Relación entre las causas de } \\
\text { las problemáticas y sus } \\
\text { impactos en diferentes países } \\
\text { del norte y del sur } \\
\text { - Despertar interés y curiosidad } \\
\text { del público, exponiendo los } \\
\text { problemas comunes y el } \\
\text { compromiso de la ciudadanía } \\
\text { en su diversidad }\end{array}$ & - No \\
\hline $\begin{array}{l}\text { 9. Hablar de cooperación } \\
\text { internacional desde una } \\
\text { visión general que } \\
\text { permita tener en cuenta } \\
\text { los diferentes aspectos y } \\
\text { diferenciar acciones de } \\
\text { desarrollo y de } \\
\text { emergencia. }\end{array}$ & $\begin{array}{l}\text { - Evitar vocabulario técnico de } \\
\text { cooperación; sencillez sin caer } \\
\text { en la simplificación } \\
\text { - No hacer presentación } \\
\text { puramente técnica de la } \\
\text { cooperación. No descuidar sus } \\
\text { dimensiones políticas }\end{array}$ & - Sí y no \\
\hline $\begin{array}{lr}10 \quad \text { Favorecer el } \\
\text { periodismo de } \\
\text { seguimiento de los } \\
\text { acontecimientos }\end{array}$ & 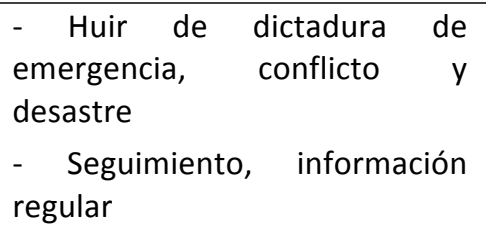 & $\begin{array}{l}\text { - Sí } \\
\text { - No }\end{array}$ \\
\hline
\end{tabular}

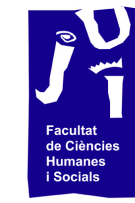

UNIVERSITAT JAUME•I 
Una vez presentados los resultados, apreciamos que esta campaña no cumple con muchas de las premisas para la información internacional responsable. En este vídeo no se están presentando ni el contexto ni las causas de las situaciones, ni tampoco se expone la problemática desde todas sus vertientes (económica, política y social). Por otro lado, no se da una voz real a sus protagonistas para que expresen la situación desde su punto de vista, ni se exponen propuestas provenientes de los países del sur que puedan enriquecer la narrativa y sirvan de inspiración en una cooperación inclusiva.

Todo ello puede tener como consecuencia la perpetuación de los marcos tradicionales de la cooperación en los que el asistencialismo rige las relaciones norte-sur y en los que se presenta a las ONGD como salvadoras, portadoras de soluciones inalcanzables por unos protagonistas incapaces y estáticos, que sin dichas ONGD serían incapaces de seguir adelante.

Un ejemplo de ello es el discurso utilizado al principio del vídeo, en el que la voz de la niña que habla describe a los trabajadores de Unicef que se van -en su gran mayoría blancos- como «[...] quienes sanaban nuestras heridas, quienes prevenían nuestras enfermedades y colmaban de conocimiento nuestras dudas». Esto genera una imagen de los protagonistas como dependientes de la ONGD, sin mostrar la cooperación desde valores de equidad, colectividad y creatividad. No se empodera a sus protagonistas ni se ponen en valor los recursos y las iniciativas que pueden surgir desde ellos.

Otro ejemplo es el escenario en que se graba el vídeo y los únicos protagonistas que se muestran, haciendo referencia a una realidad muy delimitada. Solo se muestra a niños de color en una población de lo que se intuye que es África. No da voz ni muestra realidades del resto de los niños del mundo, de distintas etnias, procedencias o situaciones a los que la ONGD también puede ayudar, perpetuando así el marco estereotipado de África como «necesitada de ayuda». Del mismo modo, no favorece una mirada crítica que contribuya a la reflexión del receptor de la comunicación ni fomenta la idea de sociedad global interconectada, sino más bien de "sociedad jerarquizada».

Por otra parte, la comunicación de este vídeo sí que cumple con otros criterios de este marco de la eficacia cultural: ofrece una representación distinta a la de los protagonistas como víctimas, así como expone una imagen de ellos como seres humanos capaces y luchadores aunque con ciertos matices, ya que, a pesar de que los protagonistas de este vídeo son niños, no se muestra a otros individuos de esas mismas comunidades ocupando escenarios decisivos, como mujeres adultas desarrollando roles distintos a los 
del cuidado del hogar y como protagonistas de la vida política y económica, para así poder transformar el marco-.

También da la voz este vídeo a los niños para que sean ellos los que cuenten su historia, en lugar de hablar solo desde la organización, lo cual ayuda a visibilizar y poner en valor a esos protagonistas transformando el discurso hegemónico en el que la información parte de la voz de la ONGD que funciona como intermediaria. Igualmente, respeta la dignidad humana al no difundir imágenes que puedan vulnerarla, mostrando a los niños protagonistas desde la alegría.

Por último, quizás lo más relevante (a mi juicio) sean las elecciones narrativas en las que se presenta una realidad distinta a la imperante en el imaginario hegemónico relativo a la cooperación, si bien por ahora es solo un imaginario en el que esos protagonistas no necesitan a la organización y esta desaparece de su realidad. Se presenta a la ONGD como prescindible y desde un discurso en el que se desea su desaparición.

Por otro lado, la campaña no está pidiendo dinero basándose en emergencias ni catástrofes, rechazando así ese discurso recurrente por parte de las ONGD que propicia esa «solidaridad del mínimo esfuerzo». El discurso no busca una recaudación motivada por los padecimientos de niños desamparados, sino que pretende un cambio estructural empoderador que suponga que la existencia de esta organización ya no sea necesaria.

Como formas de mejorar hacia una mayor eficacia cultural, si se quiere realmente conseguir ese cambio estructural, hace falta una comunicación que lo facilite, por lo que se debe dar visibilidad a las causas y los contextos tanto de las desigualdades como de las relaciones de poder que las facilitan y perpetúan. Asimismo, es importante ofrecer soluciones y que estas provengan de fuentes diversas, para así empoderar a los que tradicionalmente han sido discriminados y silenciados, convirtiéndolos en actores sociales capaces, creativos y con recursos.

Por último, y en relación con la teoría de los marcos de Lakoff, en el vídeo se parte de la idea del discurso tradicional hegemónico de la superioridad y necesidad de la ONGD, y aunque se ofrece después una visión distinta de esa relación entre ONGD-protagonistas en virtud del giro narrativo, al comunicar desde un marco - aunque sea con el fin de criticarlo-, se corre el riesgo de caer en su refuerzo.

Por ese motivo recomendaría la construcción de un marco de comunicación alternativo en el que no se apele a situaciones tradicionales de desigualdad ni siquiera para desmontarlas, sino que cree una nueva posibilidad de relaciones en las que esas desigualdades y violencias dejen de tener sentido. 
El análisis aquí presentado aborda la cuestión de la eficacia cultural en la comunicación de las ONGD, estudiando el caso concreto de la campaña \#CierraUnicef de Unicef que llevó a cabo durante el año 2017 con la metodología del Vademécum para una información internacional responsable del proyecto Devreporter.

Puesto que la campaña \#CierraUnicef es amplia, tiene ya un recorrido en el tiempo y está formada por muchos tipos de comunicaciones, principalmente su página web, se ha decidido delimitar el objeto de estudio al vídeo de la campaña en concreto. Sin embargo, dejo la línea de investigación de la página web abierta para posibles trabajos futuros, considerando para este caso más apropiado hacerlo mediante la metodología DOCHAS, más enfocada a la comunicación desde las imágenes.

Tras este análisis basado en el Vademécum enmarcado en la metodología de la eficacia cultural, y a pesar de la limitación del objeto de estudio, se puede afirmar que este vídeo enmarcado en esta campaña de \#CierraUnicef sí que recoge ciertos rasgos de la eficacia cultural por presentar un discurso en el que los protagonistas no son retratados meramente como víctimas, además de incapaces e inmóviles, y a través del cual se anima a que las ONGD aspiren a ser prescindibles. Sin embargo, es cierto que no cumple otros aspectos, como el de proporcionar el contexto y las causas de las problemáticas protagonistas en la cooperación, ni da visibilidad ni voz propia a las diversas fuentes y soluciones. Tampoco plasma una lucha conjunta de todas las esferas (incluida la política) para lograr un cambio sustancial y la construcción de un nuevo marco más igualitario.

Por lo tanto, tal y como hemos visto en los apartados anteriores, sería interesante aplicar códigos que lleven a unos planteamientos más eficaces culturalmente a largo plazo, puesto que Unicef es una organización que trabaja desde hace décadas a nivel estructural. Si lo que se pretende es un cambio en este sentido, es necesaria una comunicación que lo facilite.

\section{Bibliografía}

Austin, John Langshaw. 1976. How to do things with words. Oxford: Oxford University Press.

Ballesteros, Carlos. 2002. "Supermercados de la solidaridad». En La ética de las ONG y la lógica mercantil, coordinado por Luis Nieto, 89-134. Barcelona: Icaria. 
de Souza, Rebecca. 2009. "Creating "Communicative Spaces": A Case

of NGO Community Organizing for HIV/AIDS Prevention». Health Communication 24 (8): 692-702

CONGDE (Coordinadora de ONG para el desarrollo, España). 1998. Código de Conducta de las ONG de Desarrollo. Acceso del 15 de diciembre de 2018. https://coordinadoraongd.org/wpcontent/uploads/2016/01/Codigo_Conducta.pdf

Darnton, Andrew y Kirk, Martin. 2011. Finding Frames: New Ways to Engage the UK Public in Global Poverty. Londres: BOND for International Development.

DEVREPORTER. 2012. Vademécum para una información internacional responsable. Acceso el 15 de diciembre de 2018. http://devreporternetwork.eu/wpcontent/uploads/2016/04/vademecum_DR_ESP.pdf

DOCHAS (The Irish Association of Non Governmental Development Organisations). 2006. Code of conduct on images and messages. Acceso del 15 de diciembre de 2018. http://www.dochas.ie/sites/default/files/Images_and_Messages .pdf

Erro Sala, Javier. 2000. «Las prácticas comunicativas de las ONGD. De la comunicación mercadeada a la construcción de una mirada comunicacional». Directorio de ONGD 2000, 51-72. Madrid: CONGDE.

-. 2003a. Descubrir y construir procesos de comunicación social (Herramientas). Bilbao: Hegoa.

-. 2003b. «ONGD: ¿comunicarse por qué y para qué? El paso de la comunicación mercadeada a la comunicación social educativa». en La publicidad en el Tercer Sector. Tendencias y perspectivas de la comunicación solidaria, editado por Vicente J. Benet y Eloísa Nos Aldás, 53-81. Barcelona: Icaria.

-. 2006. «¿Pensar la comunicación o revisar el modelo de organizaciones no gubernamentales para el desarrollo (ONGD)?». En Medios de comunicación y solidaridad: reflexiones en torno a la (des)articulación social, editado por Eloísa Nos Aldás y María José Gámez Fuentes, 89-106. Castellón: Servei de Publicacions de la Universitat Jaume I.

FCONGD (Federación Catalana de ONGD). 1997. Código ético y de conducta. Barcelona: FCONGD.

Habermas, Jürgen. 1987. Teoría de la acción comunicativa. Madrid: Taurus.

Lakoff, George. 2007. No pienses en un elefante: lenguaje y debate político. Madrid: Editorial Complutense. 
Magallón, Carmen. 2012. Contar el mundo. Una mirada sobre las relaciones internacionales desde la vida de las mujeres. Madrid: Cuadernos inacabados. Horas y horas.

Mesa, Manuela. 2013. Visibles y transgresoras: narrativas y propuestas visuales para la paz y la igualdad. Fundación Cultura y Paz.

Nos Aldás, Eloísa, ed. 2003. La publicidad en el tercer sector. Tendencias y perspectivas de la comunicación solidaria. Barcelona: Icaria.

-. 2007. Lenguaje publicitario y discursos solidarios. Eficacia publicitaria, ¿eficacia cultural? Barcelona: Icaria.

—. 2010. «Comunicación, cultura y educación para la solidaridad y el desarrollo». En Comunicando para la solidaridad y la cooperación. Cómo salir de la encrucijada, editado por Javier Erro Sala y Teresa Burgui, 113-135. Pamplona: Foro de Comunicación, Educación y Ciudadanía.

Nos Aldás, Eloísa, Amador Iranzo y Alessandra Farné. 2012. «La eficacia cultural de la comunicación de las ONGD: los discursos de los movimientos sociales actuales como revisión». CIC. Cuadernos de Información y Comunicación 17: 209-237.

Rizzardini, Marco. 2002. "La producción de conocimiento y comunicación de las ONGD. Entre la ideología dominante y un imaginario social alternativo». En Las ONG y la política, editado por Marisa Revilla Blanco, 286-345. Madrid: Istmo.

Saiz Echezarreta, Vanesa. 2009. La solidaridad, espacio de mediación de los sentimientos morales. Análisis de la publicidad de las ONGD. Tesis doctoral. Madrid: Departamento de Periodismo III, Facultad de Ciencias de la Información. Universidad Complutense de Madrid.

Santolino, Montse. 2010. «Recuperando la esencia: Las ONGD como agentes de comunicación para el cambio social». En Comunicando para la Solidaridad y la Cooperación. Cómo salir de la encrucijada, editado por Javier Erro Sala y Teresa Burgui, 221256. Pamplona: Foro de Comunicación, Educación y Ciudadanía.

UNICEF. 2017. \#CierraUnicef. Acceso del 15 de diciembre de 2018 https://vimeo.com/207617226 